\title{
Elevated high-sensitivity cardiac troponin is associated with hypertrophy and fibrosis assessed with CMR in patients with hypertrophic cardiomyopathy
}

Frank Gommans ${ }^{1 *}$, Jeannette Bakker ${ }^{3}$, Etienne Cramer ${ }^{1}$, Michael A Fouraux ${ }^{4}$, Maurice J Kurvers ${ }^{2}$, Freek W Verheugt ${ }^{1}$ , Marc A Brouwer', Marcel Kofflard ${ }^{2}$

From 16th Annual SCMR Scientific Sessions

San Francisco, CA, USA. 31 January - 3 February 2013

\section{Background}

High-sensitivity (hs) cardiac troponin is a valuable biomarker of myocardial injury and frequently elevated in patients with hypertrophic cardiomyopathy (HCM). Using cardiovascular magnetic resonance (CMR) the HCM phenotype can be characterized in great detail with fibrosis as a key finding with prognostic impact. Therefore, our aim was to investigate whether elevated troponin levels in patients with clinical HCM were associated with LV hypertrophy and fibrosis as assessed with CMR.

\section{Methods}

In 62 clinical HCM patients (58\% males, mean age $51 \pm$ 15 years) hs-troponin $\mathrm{T}$ was determined with a highsensitivity assay (Roche Diagnostics). The lower detection limit is $0.003 \mathrm{pg} / \mathrm{l}$ and an elevated hs-troponin is defined as a concentration $\geq$ the $99^{\text {th }}$ percentile reference limit $(\geq 0.014 \mathrm{pg} / \mathrm{l})$. CMR with late gadolinium enhancement (LGE) was performed (Philips Achieva 1.5T) to assess LV mass indexed to body surface area, maximal wall thickness (MWT) and fibrosis. LV mass, MWT and the presence and extent of LGE were assessed (QMass 7.0, Medis) and compared between HCM patients with and without an elevated hs-troponin using Mann Whitney U or Fisher exact testing.

\section{Results}

Hs-troponin was detectable in $46 \mathrm{HCM}$ patients $(74 \%)$, of whom 16 patients had an elevated hs-troponin level. The median LV mass and MWT were higher in HCM patients with an elevated hs-troponin $(\mathrm{p}<0.001)$. The difference in the presence of fibrosis was almost statistically significant between groups. Notably, if present, the extent of fibrosis was higher in patients with an elevated hs-troponin $(\mathrm{p}=0.04)($ Table 1$)$.

Table 1

\begin{tabular}{|c|c|c|c|c|}
\hline & Total $N=62$ & Troponin not elevated $\mathrm{N}=46$ & Troponin elevated $\mathrm{N}=16$ & P \\
\hline LV mass indexed to BSA $\left(\mathrm{g} / \mathrm{m}^{2}\right)$ (median; IQR) & $65 ; 52-91$ & $61 ; 51-81$ & $101 ; 67-130$ & 0.001 \\
\hline Maximal LV wall thickness (mm) (median; IQR) & $18 ; 13-21$ & $16 ; 13-20$ & $21 ; 18-24$ & 0.002 \\
\hline Fibrosis present $\mathrm{n}(\%)$ & $31(50 \%)$ & $20(44 \%)$ & $11(69 \%)$ & 0.08 \\
\hline Fibrosis extent in LGE positive patients (\%) (median; IQR) & $10 ; 5-14$ & $7 ; 3-12$ & $14 ; 9-19$ & 0.04 \\
\hline
\end{tabular}

${ }^{1}$ Cardiology, Radboud University Nijmegen Medical Centre, Nijmegen,

Netherlands

Full list of author information is available at the end of the article

(c) 2013 Gommans et al; licensee BioMed Central Ltd. This is an Open Access article distributed under the terms of the Creative 


\section{Conclusions}

Elevated troponin levels assessed with a high-sensitivity assay are common in HCM patients and associated with specific features of HCM such as hypertrophy and maximal wall thickness. Our findings are indicative of troponin as a potential surrogate marker of myocardial injury in the form of fibrosis. Future studies will have to address this issue more elaborately especially with regard to the potential prognostic value of troponin in these patients.

\section{Funding}

None.

\section{Author details}

${ }^{1}$ Cardiology, Radboud University Nijmegen Medical Centre, Nijmegen,

Netherlands. ${ }^{2}$ Cardiology, Albert Schweitzer Hospital, Dordrecht, Netherlands. ${ }^{3}$ Radiology, Albert Schweitzer Hospital, Dordrecht, Netherlands. ${ }^{4}$ Clinical

Chemistry, Albert Schweitzer Hospital, Dordrecht, Netherlands.

Published: 30 January 2013

doi:10.1186/1532-429X-15-S1-P144

Cite this article as: Gommans et al:: Elevated high-sensitivity cardiac

troponin is associated with hypertrophy and fibrosis assessed with CMR

in patients with hypertrophic cardiomyopathy. Journal of Cardiovascular

Magnetic Resonance 2013 15(Suppl 1):P144.

Submit your next manuscript to BioMed Central and take full advantage of:

- Convenient online submission

- Thorough peer review

- No space constraints or color figure charges

- Immediate publication on acceptance

- Inclusion in PubMed, CAS, Scopus and Google Scholar

- Research which is freely available for redistribution

Submit your manuscript at www.biomedcentral.com/submit 